\title{
Um acidente no relato, um atentado na edição; e outras reflexões acerca das práticas jornalísticas
}

Angela Zamim

Reges Schwaab

Resumo: A crítica jornalística articulada à experiência é o elemento central deste artigo, que se debruça sobre fragmentos de textos em que os jornalistas elaboram apreciações sobre as práticas jornalísticas. Se o trabalho do jornalista é marcado por essas práticas, em alguma medida, é possível observá-las funcionando no interior das narrativas, em movimentos de afirmação ou resistência gestados no interior do próprio jornalismo. O presente texto trabalha as respostas dos jornalistas Ramón Lobo e Joe Sacco, respectivamente em Cuadernos de Cabul e Notas sobre Gaza, aos processos jornalísticos de edição, geralmente silenciados em meio ao cotidiano do ambiente das redações. Suas leituras deslocam o jornalismo de um lugar hegemônico cujos processos e controles se naturalizam se não suficientemente expostos. A escuta atenta dessa narrativa faz ecoar questões pertinentes ao desafio diário do trabalho de reportagem.

Palavras-chave: práticas jornalísticas; livros de repórter; crítica.

Abstract: Accident at reporting, attack at editing and other reflections on journalistic practices - Journalistic criticism articulated with experience is the core element of this paper that examines fragments of texts in which journalists talk about journalistic practices. If these practices have marked to some extent a reporter's work, it is possible to observe them operating within the narratives in movements of affirmation or resistance created by the journalism itself. This text examines the answers given by journalists Ramón Lobo and Joe Sacco on Cuadernos de Cabul and Notas sobre Gaza, respectively, about journalistic processes of the edition, usually silenced in the daily environment of the newsroom. These readings move journalism from a hegemonic place where processes and controls are naturalized if they are not exposed enough. The intently listening to these narratives echoes important questions regarding the daily challenge of news reporting.

Keywords: journalistic practices; journalist books; critics. 


\section{Considerações iniciais}

Procedimentos regulares, repetidos cotidianamente, formam um regime das práticas (FOUCAULT, 2005) dos processos que estruturam e organizam rotinas, determinam o fazer, colocando-se como adequados a um modo de objetivação jornalística. É no exercício em organizações jornalísticas, com suas políticas editoriais e controles e em meio a valores profissionais e a regras que disciplinam a recolha e o relato dos acontecimentos que os jornalistas forjam-se enquanto tal. ${ }^{1}$ Se o trabalho do jornalista é marcado por estas práticas, em alguma medida, é possível observá-las funcionando no interior das narrativas jornalísticas.

Sobre as práticas individuais, contudo, incidem controles empresariais e editoriais que silenciam temáticas e acontecimentos, alteram a linguagem e controlam condutas, estabelecendo as condições de produção de significados. Os estudos de Jornalismo, todavia, pouco têm se dedicado a localizar, nas narrativas, algum índice destes controles. ${ }^{2}$ O presente artigo se volta à apreensão do que não se diz; do silêncio sobre certas práticas jornalísticas cotidianas ao tomar para análise "espaços outros" (FOUCAULT, 2009) que não os do Jornalismo seriado e periódico. Livros escritos por jornalistas ${ }^{3}$ são assumidos como instância de acolhimento de críticas ao jornalismo e de transgressão, ${ }^{4}$ enquanto o que escapa ao padrão, ao código, à norma. Os livros Cuadernos de Cabul e Notas sobre Gaza, respectivamente dos jornalistas Ramón Lobo e Joe Sacco, respondem a processos jornalísticos de edição, geralmente silenciados em meio às práticas jornalísticas cotidianas no ambiente das redações. ${ }^{5}$

A crítica jornalística articulada à experiência é o elemento central deste artigo, que se debruça sobre fragmentos de textos em que os jornalistas elaboram apreciações das práticas do campo. O objeto da crítica de Lobo (2010) e Sacco (2010) não é o mundo, mas o discurso de um outro, que edita as reportagens, logo, os acontecimentos. Considera-se a crítica como um discurso sobre um discurso; uma linguagem segunda; uma metalinguagem, exercida sobre uma linguagem primeira (linguagem objeto).

1 De maneira sistemática, desde os anos 1970, os valores profissionais e as rotinas produtivas são objeto de estudo (FISHMAN, 1983; GANS, 1979; MOLOTCH E LESTER, 1999; SOLOSKI, 1999; TUCHMAN, 1983).

2 Recorrentemente pesquisadores e jornalistas dedicam-se a compreender os tensionamentos próprios ao sistema de produção jornalística. Fazem isso, especialmente, a partir de reflexões teóricas ou por meio de enquetes e entrevistas com jornalistas. Contudo, apesar da dificuldade de localizar na narrativa jornalística marcas que indicam controles, que assinalam processos de edição ou índices de autocensura, a presente pesquisa tem se dedicado a empreender este percurso para uma sondagem do jornalismo contemporâneo.

3 Ver "livros de repórter" (MAROCCO, 2011).

4 A reportagem constitui-se em lugar para a transgressão (BOFF, 2011), independentemente do suporte. Todavia, outros espaços narrativos, advindos ou não do jornalismo tradicional, por suas características, "desestabilizam algumas certezas da prática jornalística e colocam em questão algumas ideias consagradas a respeito do interior da profissão" (MARTINO, 2009, p. 271). Via exegese, permitem refletir sobre as práticas em meio à narrativa.

5 " [...] os mecanismos processuais e prescritivos de como trabalhar já contêm as formas de controle da expressão. Geram rotinas produtivas cujo sentido é o de neutralizar as especificidades e as características do fazer, do trabalhar de cada um" (FÍGARO et al, 2015, p. 229). Pesquisadores têm se dedicado a tratar dos silêncios do jornalismo (MAROCCO, 2012; ZAMIN, 2012; FÍGARO, 2013), como da autocensura e de sua incorporação ao ethos do jornalista (LIMA, 2011; ZAMIN, 2012; FÍGARO, NONATO, 2014). 


\section{Da experiência e da crítica jornalística}

Desde Kant, a crítica é uma atitude reflexiva diante do mundo,

[...] de confronto com o mundo, motivada ou não pela ação dos outros, que nasce da elaboração intelectual do sofrimento que eventualmente sentimos em nós e nos outros e que, pela via da exploração da nossa capacidade de raciocínio e imaginação criadora, procura entender suas origens, características e perspectivas de superação. (RÜDIGER, 2014, p. 122).

A tradição crítica inaugurada em 1784 pelo filósofo alemão no artigo de jornal O que é a Aufklärung?, que indaga acerca do presente, da atualidade e das experiências possíveis, levou Foucault a examinar "os problemas de nossa época a partir das margens [...] para estruturar uma atitude crítica diante do presente" (RÜDIGER, 2014, p. 204). Para Foucault (1990), a interrogação kantiana se configura em uma ontologia do presente, não uma analítica da verdade. Kant é o inaugurador dessa preocupação com o presente. Centra-se em um elemento do presente, o acontecimento com valor de signo, colocando-se como alguém que tem papel a desempenhar nesse processo.

Como Kant, Foucault se utilizou do espaço dos jornais. Mas, para além de Kant, criticou o jornalismo e fez dele espaço de transgressão ao dedicar-se ao exercício da reportagem. Foucault sugere que se retire a carga negativa da transgressão, o corte ou afastamento deixando o que nela pode indicar diferença. Para ele (2009, p. 32), transgressão é "um gesto relativo ao limite; e aí, na tênue espessura da linha, que se manifesta o fulgor de sua passagem, mas talvez também sua trajetória na totalidade, sua própria origem".

Marocco (2014, p. 392) afirma que "Foucault praticou e formulou um modo de fazer reportagem". Por meio do que chamou de "reportagens de ideias", sugeriu que o Jornalismo se deslocasse de seu lugar hegemônico para abarcar o presente por outra lógica: "O que está acontecendo com nosso presente, que não chega até nós" (MAROCCO, 2008, p. 44). A exemplo de Kant, vislumbra-se, na interrogação de Foucault, a preocupação com o presente.

A interrogação colocada pelo pesquisador francês pode ser objetivada como ferramenta de crítica das práticas jornalísticas, permitindo analisar o que escapa aos controles e silenciamentos que perpassam os processos da produção jornalística. Há no jornalismo sistemas de crítica como, por exemplo, a crítica literária; também a atividade profissional de crítica, a análise da mídia na própria mídia, o ombudsman. Interessanos, todavia, percorrer fragmentos de textos em que os jornalistas examinam como os acontecimentos se engendram. Se o jornalismo se legitima pela autoridade da fonte, quem pode afirmar determinada coisa? Se o jornalismo se movimenta a partir da atualidade do acontecimento, como abarcar a rede discursiva que ele aciona, uma vez que os acontecimentos existem quando submetidos à ordem do discurso, por uma interpretação que procura comunicar a experiência? 
A mediação exercida pelo Jornalismo permite-lhe produzir um determinado saber, nos termos de Foucault (2010). Segundo Castro (2009, p. 394), "Foucault entende por saber as delimitações das relações entre: 1) aquilo que se pode falar em uma prática discursiva (o domínio dos objetos); 2) o espaço em que o sujeito pode situar-se para falar dos objetos (posições subjetivas); 3) o campo de coordenação e de subordinação dos enunciados, em que os conceitos aparecem, são definidos, aplicam-se e se transformam; 4) as possibilidade de utilização e de apropriação dos discursos". O termo saber, assim como poder, não tem outro papel que o metodológico para evitar jogar com a perspectiva de legitimação como fazem os termos conhecimento e dominação.

É interessante contrapor essa perspectiva com o esforço que o próprio Foucault faz para que o jornalismo se desloque de seu lugar hegemônico. No artigo "As reportagens de ideias", publicado originalmente em novembro de 1978, no jornal italiano Corriere della Sera, Foucault (2008, p. 50) afirma que "é preciso assistir ao nascimento das ideias e à explosão da força delas [...] dentro dos acontecimentos nos quais elas manifestam sua força, nas lutas que se travam pelas ideias, contra ou com elas". Para tanto, experimentou um movimento em que jornalistas e intelectuais - juntos - trabalharam na confluência de acontecimentos e ideias.

Não há reportagem, em nosso entendimento, que não se torne um fragmento de jornalismo, um pedaço que só existe porque existe em torno dele, antes e depois dele, algo como a continuidade do jornalismo, mas que, em suas margens e/ou com ele, pode formar duas figuras estranhas. Uma delas é a figura da transgressão, do modo transgressivo de reconhecimento da época em que se vive, na palavra ou na imagem transgressiva (MAROCCO, 2008, p. 34).

Conforme enunciado por Marocco (2008), o modo transgressivo de reconhecimento do presente, uma das figuras estranhas que se formam nas bordas, se dá a ver se e quando os repórteres a incorporam à reportagem.

\section{"Las palabras también son una arma de destrucción"}

Ramón Lobo 6 publicou no jornal espanhol El País, em 2009, um conjunto de textos sobre o Afeganistão, escritos em dois momentos: de 11 a 29 de agosto, véspera do primeiro turno das eleições naquele país, e de 2 a 17 de novembro, quando do segundo turno. No jornal, digital e em papel, foram publicadas reportagens sobre as eleições presidenciais. Já a coluna Cuadernos de Kabul, cujos textos falam dos afegãos, de suas vidas e rotinas, de suas necessidades, foi publicada somente na versão digital. Ela difere, quanto ao conteúdo

6 Lobo trabalhou no El País como redator de Internacional de agosto de 1992 a novembro de 2012. Foi correspondente do jornal em diversos conflitos: Croácia, Sérvia e Kosovo, Bósnia-Herzegovina, Albânia, Chechênia, Iraque, Líbano, Argentina, Haiti, Ruanda, Nigéria, Guiné Equatorial, Serra Leoa, Uganda, Congo,

Zimbábue, Namíbia e Filipinas. 
e ao formato, das reportagens factuais produzidas pelo correspondente no mesmo período e em menor número. Também sob a designação de Cuadernos de Kabul, agora como antetítulo, $^{7}$ o correspondente publicou textos semelhantes aos da coluna do jornal em seu blog pessoal, En la boca del lobo. ${ }^{8}$ No primeiro deles, informou que subiria ao blog o conteúdo da coluna porque acreditava que não teria energia nem palavras para os dois espaços, porém neste espaço apresentou um conjunto maior de textos. ${ }^{9}$

Em 2010, Ramón Lobo publicou as colunas - do jornal e do blog - em um livro que traz como nome a designação já empregada, Cuadernos de Kabul. Todavia, os textos não foram simplesmente deslocados de um lugar ao outro. Lobo (2010) os retocou, eliminando ou acrescentando descrições: "Los cuadernos, una mirada literária, personal y humana de la misma realidad, fueron un complemento novedoso, al menos para mí, a una información clásica", destaca o jornalista na abertura do livro. No movimento de cruzar esses textos porque o livro nos levou ao blog, que nos levou à coluna no jornal e assim sucessivamente, em ordem cronológica inversa às construções operadas por Lobo - descortina-se um "posso vir a ser", do jornalista, forjado no encontro com o Outro e com os acontecimentos, tanto pela experiência do contato como por atribuir-lhe um sentido singularizado.

No blog, em post de 13 de agosto de 2009, Lobo faz referência a um acidente envolvendo um fotógrafo espanhol. Na coluna do jornal, na mesma data, em Desagradable recordatorio para los testigos de la guerra, a palavra acidente é substituída por atentado. Este mesmo termo já havia sido empregado pelo jornal no dia anterior, em matéria sobre o ocorrido assinada pela agência Reuters, Un fotógrafo español, herido en un atentado en Afganistán. ${ }^{10}$ Em post posterior, de 14 de outubro, Verbos y sustantivos con carga ideológica, Lobo fala da conotação política da linguagem, mas não relaciona o texto a algum acontecimento ou controle específico. É no livro Cuadernos de Kabul que fica evidente a relação entre este post e o mencionado anteriormente, uma vez que ali há a composição de um único texto. É no livro que Lobo revela a substituição do termo acidente por atentado por parte de um dos editores de El País digital. Os leitores da série Cuadernos de Kabul, no blog, acessaram um texto que menciona um acidente, enquanto os leitores da coluna, no jornal de referência, leram atentado. Somente no livro o jornalista fala da troca de palavras e de como ela significa.

No jornal se lê:

La noticia del atentado sufrido por el fotógrafo Emilio Morenatti y el camarógrafo indonesio Andi Jatmiko en una carretera de Kandahar ha conmocionado a la creciente colonia de periodistas en Kabul (LOBO in: EL PAÍS, 2009, s/p).11

7 Antetítulo, ou chapéu, ou cartola, é o elemento que precede o título principal. Consiste em uma definição temática que em muitos casos agrega informação. Admite-se a continuidade da leitura com o título, apesar de não ser uma exigência.

8 Disponível em: <http://www.ramonlobo.com>. Acesso em 1/12/2015

9 No artigo, o termo coluna fará referência à coluna Cuadernos de Kabul publicada em El País; o termo post será empregado quando se tratar do blog do jornalista.

10 Disponível em: <http://internacional.elpais.com/internacional/2009/08/12/actualidad/1250028008_850215.html>

11 Disponível em: <http://internacional.elpais.com/internacional/2009/08/13/actualidad/1250114407_850215. html>. 
No blog:

La noticia del accidente del fotógrafo Emilio Morenatti y del camarógrafo indonesio Andi Jatmiko en una carretera de Kandahar ha conmocionado a la creciente colonia de periodistas en Kabul. (LOBO, 2009, s/p) ${ }^{12}$.

Apenas no blog, dois meses mais tarde:

En los medios de comunicación occidentales se califica de atentados los ataques contra objetivos militares en Afganistán. Es otra prueba de la carga política que tiene el lenguaje - contra la que los periodistas deberíamos estar alerta - porque una guerra consiste en atacarse y causarse bajas mutuamente. $(\mathrm{LOBO}, 2009, \mathrm{~s} / \mathrm{p})^{13}$.

No livro:

La noticia del accidente del fotógrafo Emilio Morenatti y del camarógrafo indonesio Andi Jatmiko, ambos de la Agencia Associated Press, conmocionó el 12 de agosto a la creciente colonia de periodistas en Kabul.

$[\ldots]$

Cuando escribí <<accidente>> para referirme a lo que había sucedido a Emilio Morenatti em uma carretera de Kandahar, um editor digital de mi periódico se sintió incómodo y la sustituyó por atentado [...]. Discutí semanas después el cambio, cuando ya no tiene remedio, pero discuto, que es una de las esencias de este trabajo: en una guerra no existen los atentados, sólo los ataques. Escribir atentado es tomar partido. Las palabras también son una arma de destrucción (2010, p. 27-30).

Ao mencionar o trabalho de edição, Ramón Lobo revela para o leitor do livro parte importante das rotinas e condicionantes da produção da notícia. A edição jornalística envolve a tomada de decisões baseada na política editorial de cada meio de comunicação. O editor encontra-se na confluência de repórteres, diretores e leitores (ou telespectadores ou ouvintes) e zela pelos interesses dos meios, como empresa e como ator político. Repórter e editor são sujeitos do discurso: enquanto o repórter faz a primeira formulação da escrita de um texto, o editor faz a primeira leitura e adequação deste texto.

Segundo Silva (2011, p. 11), a prática do jornalismo desde o exterior, como correspondente, enviado, freelancer ou stringer, "amplifica as características e os problemas da profissão", tanto para os jornalistas como para os editores. "A correspondência internacional [...] é a que dá mais dificuldade para os editores (porque estes estão distantes do local dos fatos e não conseguem exercer o mesmo tipo de controle que têm sobre os repórteres locais)", acrescenta. Na edição do texto, todavia, um sutil exercício de controle pode emergir, como no caso citado.

12 Disponível em: <http://www.ramonlobo.com/2009/08/13/cuadernos-de-kabul-los-empotrados-y-la-guerra/>.

13 Disponível em: <http://www.ramonlobo.com/2009/10/14/verbos-y-sustantivos-con-carga-ideologica/>. 
Ao mostrar que o discurso é marcado por escolhas que visam a dotar de sentido os acontecimentos do mundo vivido; especialmente, ao assinalar sua discordância com a alteração de seu relato - o acidente descrito pelo jornalista se tornou atentado após a edição -, Lobo (2010) elabora, a seu modo, uma crítica das práticas jornalísticas, mais precisamente do processo de edição. A crítica que parte da e chega à experiência. O trabalho em áreas de conflito leva-o a uma compreensão distinta daquela de quem fica na redação. O objeto de sua crítica não são as ocorrências do mundo, mas o discurso que se impõe sobre o seu pelo processo de edição jornalística.

Lobo faz do blog pessoal e do livro lugares de crítica das práticas que acabam silenciadas porque cotidianas; de questionamento e subversão das relações de poder que perpassam o fazer jornalístico. Porque o jornalismo, a um só tempo, constitui-se de e constitui relações de poder, abre possibilidade para a resistência, nos termos de Foucault (2010). Ao interrogar-se acerca das condições de existência das relações de poder, permitindo-nos acessá-las, o jornalista espanhol transcende o modo de fazer, ou de narrar o acontecido e, a seu modo, indaga-se acerca do presente que chega pelo Jornalismo. Há aí um ponto de contato com Foucault, quando este se interroga: "o que está acontecendo com nosso presente, que não chega até nós" (in: MAROCCO, 2008, p. 44).

\section{"Esse episódio [...] não merece ser relegado à obscuridade"}

Interrogação semelhante foi a que moveu Joe Sacco a produzir reportagens em quadrinhos sobre a população palestina na Cisjordânia e na Faixa de Gaza, sobre a limpeza étnica sérvia na Bósnia, entre outros temas, como que "fadado a seguir os rastros de guerras e questões humanitárias" (MENA, 2011, s/p). Entretanto, poderíamos formular sua questão de outro modo: o que aconteceu em nosso passado que, mesmo tocando em nosso presente, não chega até nós?

Em 2001, quando Sacco e o repórter Chris Hedges se preparavam para ir à Faixa de Gaza como enviados especiais da revista estadunidense Harper's, durante os primeiros meses da Segunda Intifada, optaram pela cidade de Khan Younis. Ainda no momento que antecedeu ao da cobertura, Sacco lembrou-se de uma citação de Noam Chomsky de um documento da ONU sobre o assassinato de um número significativo de civis nesta localidade, em 1956, ${ }^{14}$ e propôs a Hedges que, caso "tivesse alguma validade e ressonância no contexto atual" (SACCO, 2010, p. VII), seria incorporado à reportagem, o que de fato ocorreu. Todavia, no processo de edição, "por alguma razão, esse trecho foi cortado pelos editores da revista" (ibid.,VII).

O incômodo que a situação provocou em Sacco, as pesquisas posteriores por ele realizadas e a crença de que o ocorrido em Khan Younis merecia vir à tona, levaram-no de volta à Gaza, em 2002 e 2003, para investigar o acontecido em 1956. A reportagem

14 Relatório Especial da Agência de Socorro e Trabalho da ONU para os Refugiados Palestinos no Oriente Próximo (United Nations Relief and Works Agency - UNRWA) sobre o período nov./dez. de 1956. 
em quadrinhos Notas sobre Gaza (2010), publicada nos Estados Unidos em 2009, é resultado deste investimento. Há, nesta descrição, pontos de contato com Ramón Lobo, ao conceber o livro como lugar de crítica à ordem jornalística. Nele, cabe falar da edição que altera a narrativa, tratar de acontecimentos que não encontram espaço na mídia periódica, trazendo aí fontes ignoradas de maneira sistemática, e buscar modos outros de constituir o jornalismo.

Fiquei bastante incomodado com isso. Esse episódio [...] não merece ser relegado à obscuridade. Porém, é lá que ele se encontra, junto com inúmeras tragédias históricas que ganham no máximo uma nota de rodapé no contexto mais amplo da história - ainda que [...] muitas vezes contenham as sementes do sofrimento e do ódio que dão forma aos acontecimentos do presente (SACCO, 2010, p. VII).

Empregada anteriormente como metáfora, a nota de rodapé torna-se elemento recorrente no livro. Há um capítulo inclusive nomeado de "Notas de rodapé". Nele se lê:

A história é capaz de sobreviver sem as notas de rodapé. Elas nem sempre são necessárias, e muitas vezes acabam desviando o foco da narrativa principal. De tempos em tempos, à medida que surgem edições mais abrangentes e atualizadas da história, algumas notas de rodapé são simplesmente descartadas. E dá para entender por quê... A história está sempre em movimento. Produz novas páginas a cada hora, a cada minuto. Digere os eventos do passado para abrir espaço aos mais recentes (SACCO, 2010, p. 9).

Ao operar entre testemunhos orais - desgastados pela memória - e documentos escassos e inacessíveis, Joe Sacco mostra a atualidade do passado e seu contrário. Segundo Sarlo (2005, p. 96), "recorremos a imagens de um passado que são, cada vez mais, imagens daquilo que é recente". O registro da memória opera entre lembrança e esquecimento (SELIGMANN-SILVA, 2003; HUYSSEN, 2000; SARLO, 2005, 2007). Para Seligmann-Silva (2003), a memória existe por meio e a partir de leituras - no plural - do passado e de modos de enquadrá-lo. Sarlo (2005), por sua vez, fala em uma conjugação entre o instante e a rememoração, como modo de, pelo segundo, tornar coerente a primeira.

Ao se referir à cobertura jornalística sobre os ataques israelenses, que matam palestinos, e os atentados palestinos, que matam israelenses, Joe Sacco (2010, p. 5) lança a indagação: "Eles poderiam usar a mesma matéria do mês passado - ou até do ano passado - e quem perceberia?", o que aponta para a repetição do mesmo, mas, especialmente, para a crítica à ordem social que faz do passado presente e do presente passado nos Territórios Ocupados da Palestina. Aponta, também, à ordem que, pelo jornalismo, se impõe, despindo de sentido histórico os acontecimentos, esvaziados pela repetição do modo de noticiá-los a partir de protocolos e enquadramentos já desgastados pelo uso. "O passado e o presente não podem ser dissociados com tanta facilidade; eles são parte da mesma sucessão implacável de eventos, uma distorção histórica", conclui Sacco (2010, p. IX). 
Se é verdade que no campo da memória atua a seleção dos momentos do passado e não o seu total arquivamento, ou seja, a memória só existe ao lado do esquecimento, por outro lado, cabe ao historiador - assim como individualmente a cada um de nós - não negar ou denegar os fatos do passado, mesmo os mais catastróficos. Como na figura do catador de trapos que Benjamin identificava com a do historiador: devemos salvar os cacos do passado e distinguir os mais valiosos dos aparentemente sem valor (SELIGMANN-SILVA, 2003, p. 77).

Sacco (2010) esboça reflexão similar ao se referir à memória e ao esquecimento, presente nos testemunhos que recolheu, e, também, aos documentos históricos que acessou. Sobre a "série de relatos pessoais sobre a matança desenfreada de jovens palestinos por soldados israelenses em Khan Younis, no dia 3 de novembro de 1956" relembra que "nem é preciso dizer que as lembranças mudam com os anos [...]. A memória torna os contornos difusos; ela adiciona e subtrai" (p. 112) e conclui: "Só quero deixar claros os problemas de se depender do relato de testemunhas para contar nossa história" (p. 116). Quanto às provas documentais, o jornalista afirma que "o relatório da ONU apresenta duas versões incompatíveis do 'incidente' em Khan Younis" (p. 118). Acrescenta que, além de escassos, os documentos estão "fora dos autos" ou "longe do alcance" (p. VIII).

A edição realizada pela Harper's, que acabou por subtrair os parágrafos escritos por Chris Hedges sobre Khan Younis - Sacco foi o ilustrador da reportagem -, mobilizou Joe Sacco a ponto de fazê-lo retornar aos Territórios Ocupados da Palestina e, especialmente, à cidade e ao acampamento de refugiados de Khan Younis e a percorrer arquivos diversos. A crítica à edição da reportagem, que abre o livro "Notas sobre Gaza", todavia, se sobrepõe uma autocrítica: Joe Sacco solicita que os leitores considerem como filtros as rememorações pessoais e a sua interpretação visual.

\section{Considerações finais}

Pela narrativa em "outros espaços" (FOUCAULT, 2009), é possível ao jornalista contar acerca das atividades "sobre si mesmo", além de dar a ver movimentos de afirmação ou resistência gestados no interior do próprio sistema. A crítica das práticas jornalísticas que toma forma nos "outros espaços" permite trabalhar de modo aproximado, e em via pouco explorada, os procedimentos e processos próprios desse fazer, ampliando a compreensão sobre os sujeitos e as mediações aí implicadas. Os livros e o blog, nos dois casos aqui citados, configuram-se em lugares de questionamento, crítica e transgressão da relação saber-poder que, historicamente, caracteriza o jornalismo e visibiliza a construção, a edição, o recorte e a disposição da narrativa. Assim, não só as ocorrências do mundo que ganham lugar pela prática jornalística são colocadas em perspectiva, mas o discurso sobre o que acontece, produto primordial do exercício periódico do jornalismo, ganha status de objeto de análise dos repórteres. Como buscamos mostrar, a crítica jornalística 
que empreendem toma forma em articulação com a experiência, e seus contornos se desenham pelo deslocamento do jornalismo de um lugar hegemônico cujos processos se naturalizam sem que sejam suficientemente expostos, numa eventual transparência que mais encobre do que mostra se pouco dissermos sobre eles.

Além disso, conforme argumenta Temple (2009), recolocando a leitura foucaultiana de Kant, o movimento da crítica será sempre necessário, uma vez que ela "tem o papel de definir as condições nas quais o uso da razão é legítimo para determinar o que se pode conhecer, o que é preciso fazer e o que é permitido esperar" (2009, p. 234). Do ponto de vista teórico-metodológico para o estudo do Jornalismo, cabe salientar, estamos imersos na questão da autonomia do sujeito e das "práticas de liberdade no âmbito das relações de poder" (ibid., p. 244).

Em ambos os casos aqui tratados, vimos que o gesto de crítica partiu de uma iniciativa individual, fruto de reflexão e vigilância de cada um dos jornalistas. Tal investigação, decorrente de duas outras pesquisas maiores e complementes, tem mostrado que a criação de outros espaços de narrar é muito devedora de uma decisão do próprio sujeito jornalista em dar a ver o processo narrativo e laboral que torna o jornalismo possível de determinado modo e não de outro. Em muitos casos, como no que observamos em Ramón Lobo e Joe Sacco, o livro tem sido lugar privilegiado da crítica, mas também os espaços virtuais e o documentário aparecem. De um lado, tais produções servem para tensionar o próprio sistema jornalístico como se algo fosse dito "de fora" sem, todavia, sair dele. É uma escuta atenta dos processos que, apesar de nascida no interior de iniciativas individuais, faz ecoar questões pertinentes ao desafio diário do trabalho de reportagem.

A crítica das práticas em outros espaços, como os livros de repórter, aparece, portanto, como objeto de pesquisa capaz de oferecer uma narrativa mais alargada, que dá a ver discrepâncias e conflitos entre sujeitos, regras e modos de operar, com reflexos da e na experiência coletiva do trabalho jornalístico. Produzidas em um espaço intervalar próprio, que herda elementos do jornalismo, da filosofia, da literatura e das ciências sociais, propõem alguma referência não condicionada aos mesmos processos do jornalismo diário ou periódico. E mesmo em um espaço outro, não abandonam índices que qualificam como jornalisticamente válidas as leituras oferecidas. Servem também como importante sumário das questões que interessam aos próprios sujeitos do campo, pois são fruto das indagações e da experiência cotidiana dos trabalhadores da reportagem, sublinhando, mais uma vez, um terreno largo a ser cientificamente explorado e que congrega as práticas cotidianas, os controles, os silenciamentos, as linhas de fuga para a produção jornalística. 
Jornalísticas (CNPq/UFSM). É doutora em Ciências da Comunicação pela Unisinos.

angelazamin@gmail.com

Reges Schwaab é professor do Departamento de Ciências da Comunicação da Universidade Federal de Santa Maria (UFSM). É doutor em Comunicação e Informação pela UFRGS.

reges.ts@gmail.com.

\section{Referências}

BOFF, F. Reportagem: transgressão nas fronteiras do jornalismo. 2011. 124f. Dissertação (Mestrado), Programa de Pós-Graduação em Ciências da Comunicação, Universidade do Vale do Rio dos Sinos. São Leopoldo, RS: 2011.

CASTRO, E. Vocabulário de Foucault. Um percurso pelos seus temas, conceitos e autores. Belo Horizonte: Autêntica, 2009.

FÍGARO, R. As mudanças no mundo do trabalho do jornalista. São Paulo: Atlas, 2013.

FÍGARO, R. NONATO, C. A autocensura como aspecto da prática no mundo do trabalho dos jornalistas. In: XXXVII Congresso Brasileiro de Ciências da Comunicação, 2014, Foz do Iguaçu. Anais. Foz do Iguaçu: Intercom, 2014.

FíGARO, R.; NONATO, C.; BULLA, O. O silêncio como prescrição para o trabalho do jornalista. In: III Colóquio Internacional Mudanças Estruturais no Jornalismo, 2015, Florianópolis. Anais. Florianópolis: Mejor, 2015, p. 228-241.

FISHMAN, M. La fabricación de la noticia. Buenos Aires: Tres Tiempos, 1983.

FOUCAULT, M. A arqueologia do saber. 7. ed. Rio de Janeiro: Forense Universitária, 2005.

. As reportagens de ideias. In: BERGER, C.; MAROCCO, B. Ilha do Presídio: uma reportagem de ideias. Porto Alegre: Libretos, 2008. p. 49-51.

Mesa redonda em 20 de maio de 1978. In: Estratégia, Poder-saber. Rio Janeiro: Forense Universitária, 2010. p. 335-351.

Prefácio à transgressão. Estética: literatura e pintura, música e cinema. 2 ed. Rio de Janeiro: Forense Universitária, 2009, p. 28-45. (Ditos e escritos III).

Qu'est-ce que la Critique?. Bulletin de la Société Française de Philosophie, Paris, t. LXXXIV, année 84, n.2, p.35-63, avr./juin. 1990.

GANS, H. J. Deciding what's news. Londres: Constable, 1980

HUYSSEN, A. Seduzidos pela memória: arquitetura, monumentos, mídia. Rio de Janeiro: Aeroplano, 2000.

KANT, I. Beantwortung der Frage: Was ist Aufklärung? In: Textos seletos. Petrópolis: Vozes, 1974.

LIMA, Venício A. de. O silêncio como forma de censura. Observatório da Imprensa, São Paulo, 22 mar. 2011. Disponível em: <http://www.observatoriodaimprensa.com.br/news/view/o-silencio-comoforma-de-censura $>$. Acesso em: 01/12/2015. 
LOBO, R. Cuadernos de Kabul. Barcelona: RBA Libros, 2010.

MARTINO, L. M. S. Teoria da Comunicação: ideias, conceitos e métodos. Petrópolis: Vozes, 2009.

MAROCCO, B. (org.). Entrevista na prática jornalística e na pesquisa. Porto Alegre: Libretos, 2012.

Os "livros de repórter", o "comentário" e as práticas jornalísticas. Revista Contracampo, Niterói, n. 22, fev. 2011, p. 116-129. Disponível em: <http://www.uff.br/contracampo/index.

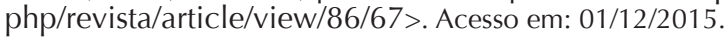

Reportagem de transgressão, um giro no tratamento da fonte jornalística. In: BERGER, C.; MAROCCO, B. Ilha do Presídio: uma reportagem de ideias. Porto Alegre: Libretos, 2008. p- 33-47.

Michel Foucault. In: CITELLI, Adilson et al. Dicionário de comunicação: escola, teorias e autores. São Paulo: Contexto, 2014. p. 388-393.

MENA, Fernanda. Desenhar conflitos é perturbador, diz Joe Sacco, que vem para a Flip. Folha de $\mathbf{S}$. Paulo. Ilustrada, 2 jul. 2011. Disponível em: <http://www1.folha.uol.com.br/ilustrada/2011/07/937534desenhar-conflitos-e-perturbador-diz-joe-sacco-que-vem-para-a-flip.shtml>. Acesso em: 01/12/2015.

MOLOTCH, H.; LESTER, M. As notícias como procedimento intencional: acerca do uso estratégico de acontecimentos de rotina, acidentes e escândalos. In: TRAQUINA, N. Jornalismo: questões, teorias e "estórias". 2. ed. Lisboa: Vega, 1999. p. 34-51.

RÜDIGER, Francisco. Crítica. In: MARCONDES FILHO, Ciro. Dicionário da comunicação. 2. ed. rev. e ampl. São Paulo: Paulus, 2014. p. 122-123.

RÜDIGER, Francisco. Foucault, Michel. In: MARCONDES FILHO, Ciro. Dicionário da comunicação. 2. ed. rev. e ampl. São Paulo: Paulus, 2014. p. 204-205.

SACCO, Joe. Notas sobre Gaza. São Paulo: Companhia das Letras, 2010.

SARLO, B. Tempo presente: notas sobre a mudança de uma cultura. Rio de Janeiro: José Olympio, 2005.

. Tempo passado: cultura da memória e guinada subjetiva. São Paulo: Companhia das Letras; Belo Horizonte: Editora UFMG, 2007.

SELIGMANN-SILVA, M. Reflexões sobre a memória, a história e o esquecimento. In: (org.). História, memória, literatura: o testemunho na era das catástrofes. Campinas: UNICAMP, 2003. p. 59-89.

SILVA, Carlos Eduardo Lins da. Correspondente internacional. São Paulo: Contexto, 2011.

SOLOSKI, J. O jornalismo e o profissionalismo: alguns constrangimentos no trabalho jornalístico. In: TRAQUINA, N. Jornalismo: questões, teorias e "estórias". 2. ed. Lisboa: Vega, 1999. p. 91-100.

TEMPLE, G. C. Aufklärung e a Crítica kantiana no pensamento de Foucault. Cadernos de Ética e Filosofia Política, n. 14, vol. 1, 2009, p. 225-246. Disponível em: <http://www.revistas.usp.br/cefp/ article/view/83328/86352 >. Acesso em: 01/12/2015.

TUCHMAN, G. La producción de la noticia: estudio sobre la construcción de la realidad. Barcelona: Gustavo Gili, 1983.

ZAMIN, A. A autocensura é um dos perigos do jornalismo. Entrevista com Josep Rovirosa Olivé. In: MAROCCO, B. (org.). O jornalista e a prática: entrevistas. São Leopoldo: Unisinos, 2012, p. 225-231.

. O questionário, a escuta das práticas e os comportamentos regulares no jornalismo. In: MAROCCO,

B. (org.). Entrevista na prática jornalística e na pesquisa. Porto Alegre: Libretos, 2012. p. 117-128. 